\title{
Turkish Insurance Companies' Risk Management Strategies and Structures: A Survey Study
}

\author{
Suna Ozyuksel ${ }^{1} \&$ Murat Gezgin $^{2}$ \\ ${ }^{1}$ Finance Institute, Head of Insurance and Risk Management Department, Istanbul Commerce University, \\ Istanbul, Turkey \\ ${ }^{2}$ Finance Institute, Insurance and Risk Management Department, PhD Student, Istanbul Commerce University, \\ Istanbul, Turkey \\ Correspondence: Murat Gezgin, Finance Institute, Insurance and Risk Management Department, PhD Student, \\ Istanbul Commerce University, Imrahor Cad. No:88/2 Beyoglu, 34445 Istanbul, Turkey. Tel: 90-533-646-8989. \\ E-mail: murat.gezgin@d12.com.tr
}

Received: May 10, 2020

Accepted: May 27, 2020

Online Published: June 20, 2020

doi:10.5539/ijef.v12n8p12

URL: https://doi.org/10.5539/ijef.v12n8p12

\begin{abstract}
Insurance industry is one of the cornerstones of both the financial system and the economy as it undertakes global risks and minimizes losses. The compensation of major losses by insurance companies means rapid recovery and resumption for investors. The insurance sector is very important for the development of the country's economy as it contributes premium volume and its support to investors as for compensation of the losses. However, the insurance sector faces a great deal of risks. Therefore, it is of importance for insurance companies to have a robust risk management system to constitute a basis for the growth of economy. Risk management enables insurance companies to identify measuring and analyzing risks, safeguard their assets, minimize potential risks and take them under control. The aim of this study is the evaluation of the risks assumed by insurance companies in Turkey and their risk management perspectives to struggle such major risks through a survey. This survey makes an evaluation about how insurance companies' risk management departments are structured, risks that insurance companies foresee, their strategies to deal with such risks. Among the important findings of the survey; Top 10 risks for insurance companies are: "interest rate and foreign exchange rate fluctuation, political risks, economic slowdown, economic crisis, regulations, cyber-attacks, incompliance with the applicable legislation, increasing competition, digitalization/insurtech, business continuity interruption" and the second finding is Turkish insurance industry's risk management set-up has a robust structure even though it has a small share in global insurance market and Turkish financial sector.
\end{abstract}

Keywords: insurance company risk management, insurance company survey, risk, risk management strategy, risk department structure, Turkish insurance industry

\section{Introduction}

Organizations face a very wide range of risks that can impact the outcome of their operations. The desired overall aim may be stated as a mission or a set of corporate objectives. The events that can impact an organization may inhibit what it is seeking to achieve (hazard risks), enhance that aim (opportunity risks), or create uncertainty about the outcomes (control risks). Risk management needs to offer an integrated approach to the evaluation, control and monitoring of these three types of risks. Risk management also needs to be supported by a framework within the organization. The combination of risk management processes, together with a description of the framework in place for supporting the process, constitutes a risk management standard. There are several risk management standards in existence, including the IRM Standard and British Standard BS 31100:2011. There is also American COSO ERM cube. The most high-profile addition to the available risk management standards is the international standard ISO 31000, first published in 2009 and updated in 2018 (Hopkin, 2018).

Enterprise Risk Management (ERM) perspective has appeared in recent years with creating additional value to risk management's traditional concept. Creating risk appetite and risk culture in the company, constituting systematically integrated techniques \& tools and making holistic approach in all business lines in the company build Enterprise Risk Management. Casualty Actuarial Society (CAS) defines ERM as "disciplines by which an 
organization in any industry assesses, controls, exploits, finances, and monitors risks from all sources for the purposes of increasing the organization's short- and long-term value to its stakeholders". Committee of Sponsoring Organization (COSO) defines ERM as "a process, effected by an entity's board of directors, managements, all other personnel, applied in strategy-setting and across the enterprise, designed to identify potential events that may affect the entity, and manage risk to be within its risk appetite, to provide reasonable assurance regarding the achievement of entity objectives". The S\&P defines ERM as follows: "Insurer has extremely strong capabilities to consistently identify, measure, and manage risk exposures and losses within the company's predetermined tolerance guidelines. There is consistent evidence of the enterprise's practice of optimizing risk-adjusted returns. Risk and risk management are always important considerations in the insurer's corporate decision-making".

The concept of risk management is one of the top items on the agenda of all companies in line with the emergence of new risks in today's world. Given the diversity and dynamics of risks, it has recently become more and more important for investors to adapt to such changes and manage risks in an effective manner in order to safeguard their position in the global market and achieve sustainability. Factors that adversely affect a company's success such as uncertainties, changes and complications help investors adopt a risk-based mentality and strategic thinking to make business plans.

Risk management is a process to be followed up as risks arise, and it covers the establishment of strategic goals, identification of risks, risk analyses, risk assessments, risk management methodologies and designation of checks, implementation of a methodology and follow-up and assessment of practices. This enables companies to achieve sustainability, incorporating risk-based mentality into long-term strategic plans. To this end, a survey was performed to evaluate the risks assumed by insurance companies in Turkey and their risk management actions and perspectives to struggle such major risks and the survey data was analyzed by non-parametric Chi-Square tests.

\section{Literature Review}

Risk management was appeared in 1950s after World War II. In addition to first article about risk management written by Russel Callagher in the Harvard Business Review in 1956, Robert I. Mehr and Bob A. Hedges developed the risk management concept in 1960s. The aim of risk management was just enhancing the productivity and efficiency of companies and it was just focused on pure risks at those times. Also, the first book called "Risk Management in the Business Enterprise" was published by Mehr and Hedges in 1963 (Gahin 1971; Outreville, 1998). During 1960s, contingency planning became more important. In the 1970s, financial risk management took place related to stock price, exchange rate and inflation rate. Also, in the 1970s self-insurance, risk retention and captive insurance companies were appeared. In 1980s, political risks were important issues for multinational companies and treasury departments were established for the financial risk management. In 1990s the use of financial tools such as forwards and futures are widely practiced in the United States (Skipper \& Kwon, 2007). In 2000s, Chief Risk Officer (CRO) titles were seen in many industries. Internal risk management systems and capital models were developed. With Sarbanes-Oxley Act of 2002 (SOX) in USA, companies started to more invest in risk management area. Especially after 2008 financial crisis in the world, risk management started to be most important topic (Hopkin, 2018).

In the beginning of ERM's birth, in 1958, Modigliani and Miller reached the end of unrelated connection between the risk management and company value, capital asset pricing (Sprcic, 2013). On the other hand, in recent years this idea has been changed by Acharyya and Mutenga. They argued that ERM adds value to companies and undergoes stages to mature. ERM creates value when the infrastructure is fully involved in the company's operations. The value creation quality depends on the level of risk integration into operations, underwriting, investment, HR, reporting, compliance, and IT functions. Insurance companies are better on implementing ERM than adopting a silo-type risk management initiative (Acharyya \& Mutenga, 2013). Other similar study was performed by Hoyt \& Liebenberg. They examined the determinants of ERM in U.S. insurance companies. The aim of this study was to determine the factors for insurance companies to estimate the relationship between ERM and companies' value. They found a positive relation between the company value and the use of ERM and appointment of CROs. The findings of this study show that size, institutional ownership and international diversification were significant in determining ERM adoption (Hoyt \& Liebenberg, 2011).

Gamba and Triantis evaluated the risk management strategies on liquidity management, derivatives hedging, operating flexibility and they found that liquidity plays a major role in risk management, justifying high levels of cash (Gamba \& Triantis, 2013). Another study found a relation between ERM and company performance indicators as environmental uncertainty, market competition, company size, company complexity, and board's 
monitoring (Gordon, 2019). In terms of connection between financial reporting and ERM, a research was performed in US with 32 participants and one of the major finding is that there is a strong connection between ERM and financial reporting (Cohen, Krishnamoorthy, \& Wright, 2017).

Enterprise Risk Management has a relationship among actuaries, corporate financial managers, underwriters, accountants, internal auditors and multidisciplinary groups of the insurance companies' employees. The effective risk management is an interdisciplinary work grounded on a holistic framework (Acharyya, 2008).

Insurance companies manage their key risks collectively in a holistic approach including investors. ERM structure in the companies should include "potential correlations of earnings from future new business with macroeconomic trends, other risks to franchise value, and sources of model risk within the company" (Hitchcox, Klumpes, Mc Gaughey, Smith, \& Taverner, 2011).

Internal and external stakeholders' awareness is advancing on risk management of insurance companies. Deighton, Dix, Graham and Skinner explored how risk management can combine the various control frameworks needed to support governance over UK insurance companies. Although all companies are not the same, so solutions to these problems change, there are several common themes associated with successful implementation. Similarly, various obstacles to success are determined (Deighton, Dix, Graham, \& Skinner, 2009).

Insurance companies have an incentive to manage capital costs through risk management. ERM helps insurers to build better risk-based decision making and capital allocation. A study was performed in insurance companies in London. ERM's decision to adopt was mainly driven by coercive, internal and normative pressures rather than mimetic ones. CRO, CEO and CFO's support for ERM in insurance sector has been shown to be the main determinants for ERM implementation. Additionally, ERM guides changes in various risk management practices such as capital allocation, underwriting and actuarial (Jabbour, 2011).

Altuntas, Berry-Stolze and Hoyt surveyed the ERM system and activities in German property-liability insurance companies. The results document significant increases in the extent to which ERM is being implemented by these German insurance companies and details the sequence of implementation of this evolving risk management process (Altuntas, Berry-Stolzle, \& Hoyt, 2011).

Acharyya and Johnson studied examining the ERM practices on European insurance companies. This study shows that the level of understanding of the nature of ERM varies significantly between the companies and different parts of the same organization. While effective ERM requires an interdisciplinary approach, the ERM which is practiced by the European-based insurers is dominated by a single discipline (Acharyya \& Johnson, 2006).

In addition to academic literature, there are some global risk management surveys and reports on insurance industry in the world. Some of them are "FERMA European Risk Manager Survey", "AON Global Risk Management Survey", "Axa-Eurasia Group Future Risks", "Risk in Focus 2020 by ECIIA", "Survey of Emerging Risks by CAS, CIA, SOA", "RIMS Enterprise Risk Management Survey", "RIMS-Marsh Strategic Risk Finance in the Era of Big Data Survey", "Insurance Banana Skins by PWC \& CSFI", "PWC Insurance Risk and Compliance Benchmarking Survey", "Most Dangerous Risks to insurers survey by Willis Towers Watson", "Allianz Risk Barometer", "Risk Survey Report by AFP and Marsh", "Insurance CRO Survey by APAC \& EY", "Global Risk Management Survey by Deloitte", "WEF Global Risks Report", "Cambridge Global Risk Index Report", "Accenture Global Risk Management Study - Insurance Report", "Emerging Risks Survey by APCIA", "Insurance Sector Emerging Risk Barometer by FFA", "Swiss Re SONAR - New Emerging Risk Insights by Swiss Re Institute".

There is no survey that directly evaluates the risks concerning the risk management of insurance companies based in Turkey. However, the FERMA European Risk Manager Survey, which was performed by the Federation of European Risk Management Associations, covers Turkey whereas its results are published in an EU-wide manner, and it offers no specific results on Turkey. Yet, there are some surveys performed in Turkey over country risks and insurance industry risks. They are "National Risks 2020", "AON Turkey Risk Management Survey 2018" and the survey "PWC\&CSFI - Risks in Insurance Industry 2019" was performed in Turkey.

\section{An Overview of the Turkish Insurance Industry}

According to Turkish Insurance Supervision Board (SDK) Annual Report 2018, Turkish Insurance Industry data set is presented below. Based on the key indicators of the year 2018, Turkey's gross domestic product (GDP) is TRY 3,7 billion and the population is 82 million. There are 17,7 million residences and 22,9 million registered vehicles in Turkey. USD/TRY exchange rate corresponded to 4,81 on average in 2018 (SDK, 2018). 
Turkey has a total of 60 insurance companies including 38 non-life, 17 life and pension and 5 life insurance companies as of 2018. In addition to these insurance companies, 2 reinsurance companies have been operating in Turkey. $68 \%$ of insurance companies based in Turkey are of international capital. There are 140 insurance and reinsurance brokerage companies, 15.782 insurance agencies, 1.243 insurance loss adjuster expert companies, 3.260 agricultural experts and 48.000 private pension intermediaries in Turkish insurance industry. The total number of employees working for the whole insurance industry is estimated to be over 200.000 (SDK, 2018).

The Turkish insurance industry produced a total of TRY 54,6 billion in premium including TRY 47,7 billion for non-life insurance and TRY 6,9 billion for life insurance in 2018. A total of 85,9 million policies were issued, and TRY 126,9 trillion in total insurance coverage were granted to insureds in 2018. TRY 126,9 trillion coverage, corresponding to 34 folds of Turkey's GDP, shows the importance of the Turkish insurance industry for the domestic economy and the steady growth (SDK, 2018).

The top 4 lines of insurance in total sum of premium produced by the Turkish insurance industry are land vehicle motor obligatory liability insurance $(30,6 \%)$, land vehicle motor own damage insurance $(17,9 \%)$, property damage insurance $(15,1 \%)$ and health insurance $(13,8 \%)$. Nearly half $(48,5 \%)$ of the total premium is produced out motor insurance lines (SDK, 2018).

Insurance agencies play a major role as a premium production source for the Turkish insurance industry. Of the premiums produced in $2018,58 \%$ of them were produced by insurance agencies, $24,5 \%$ by bank agencies, $12 \%$ by insurance $\&$ reinsurance brokers, and $4 \%$ directly by insurance companies (SDK, 2018).

The total assets of the whole financial sector in Turkey amounted to TRY 4,3 trillion in 2018, and the assets of the insurance industry, which stood at TRY 178,4 billion, corresponded to $4,17 \%$ of the whole financial sector.

While the Turkish Insurance sector has been growing, it keeps its financial solidity. The capital adequacy ratio of the insurance companies has been realized as $143 \%$ for non-life companies and 336\% for life and pension companies as of 2018. These data have revealed that both sectors have sufficient equity in order to fulfill their responsibilities (SDK, 2018).

On the other hand, the global premium production rose by 1,5\% in 2018 in real terms compared to the previous year. Life insurance premium amounted to USD 2,8 trillion and non-life insurance amounted to USD 2,4 trillion, bringing the total sum of insurance premium to USD 5,2 trillion. As for the breakdown of the total sum of premium by continents; USD 1,76 trillion was produced in America, USD 1,75 trillion in Europe, Middle East, Africa (EMEA) countries, and USD 1,68 trillion in Asian countries. In terms of the breakdown of total sum of premium by the development level of countries, USD 4,1 trillion were produced in advanced/developed countries while USD 1,1 trillion were produced in emerging countries (SwissRe, 2019).

The premium production per capita in the global insurance industry is USD 682 for global average, USD 4.377 for North America, USD 3.276 for advanced EMEA countries, USD 85 for emerging EMEA countries, and USD 127 for Turkey. The ratio of the premium production to GDP in the global insurance industry is $6,09 \%$ for the global average, $7,17 \%$ for North America, 7,61\% for advanced EMEA countries, 1,99\% for emerging EMEA countries, and 1,33\% for Turkey (SwissRe, 2019).

For the comparison of the Turkish insurance industry to the global insurance market, the share of Turkish premium production in the world, the ratio of premium production to GDP, premium growth rates and premium production per capita are presented below (Table 1).

Table 1. Turkish insurance industry's share in the global insurance market

\begin{tabular}{lccccc}
\hline & $\mathbf{2 0 1 4}$ & $\mathbf{2 0 1 5}$ & $\mathbf{2 0 1 6}$ & $\mathbf{2 0 1 7}$ & $\mathbf{2 0 1 8}$ \\
\hline Turkey's Premium Share in the Global Direct Insurance Premium & & & & & \\
Volume (\%) & 0.25 & 0.25 & 0.28 & 0.26 & 0.22 \\
Global Premium Volume / GDP (\%) & 6.17 & 6.23 & 6.3 & 6.13 & 6.09 \\
Turkey Premium Volume / GDP (\%) & 1.24 & 1.3 & 1.52 & 1.42 & 1.33 \\
Global Direct Premium Real Growth Rate (\%) & 3.5 & 3.8 & 3.1 & 1.5 & 1.5 \\
Turkey Direct Premium Real Growth Rate (\%) & 1.66 & 12.65 & 26.64 & 3.43 & -1.46 \\
Global Direct Premium Volume Per Capita (USD) & 662 & 621 & 638 & 650 & 682 \\
Turkey Direct Premium Volume Per Capita (USD) & 149 & 141 & 164 & 149 & 127 \\
\hline
\end{tabular}

Source: Swiss Re Sigma No:3/2019 World Insurance Report \& SDK Annual Report on Insurance \& Pension 2018. 


\section{Survey on Risks and Risk Management for Turkish Insurance Companies}

\subsection{Purpose of the Survey, General Information about the Survey and the Profile of the Respondents}

\subsubsection{Purpose of the Survey}

The purpose of this study is to evaluate the risks assumed by insurance companies in Turkey and their risk management actions and perspectives to struggle such major risks through a survey. The survey makes an assessment about how risk management departments are structured at insurance companies, risks that insurance companies foresee, their strategies adopted to deal with such risks, and insurance policies that insurance companies buy for their risk management.

\subsubsection{General Information about the Survey}

Drawn up based on the questions of the FERMA European Risk Manager Survey performed by the Federation of European Risk Management Associations for all industries in European countries, the questions of the survey were disseminated in 2019 among CEOs, CROs, CFOs, managers of internal control \& risk management and internal audit through a questionnaire and face-to-face interviews and one single response was received from each insurance companies in Turkey.

The universe of the survey consists of 60 insurance companies that currently operate in Turkey in 2019 according to Insurance Association of Turkey (TSB). Composed of 51 questions, the survey was performed between March and July 2019, with responses from 50 insurance companies (83\% participation) out of 60 in total. The survey consists of 5 chapters. The first chapter of the survey gives an insight into the demographics of the respondents. The second chapter includes general information about the insurance companies that the respondents work for. The third chapter offers information about the risk management departments of insurance companies. The fourth chapter offers general information about risks assumed by insurance companies and their strategies adopted to deal with them. The fifth chapter of the survey offers general information about insurance policies that insurance companies buy for their risk management purposes.

\subsubsection{Profile of the Respondents}

Of 50 respondents, $30(60 \%)$ are men and $20(40 \%)$ are women. Of the respondents, 38 of the risk managers (76\%) are married while 12 of them (24\%) are single. The age of the risk managers ranges from 30 to 60 , and their average age is " 41 ". $75 \%$ of the respondents are " 36 to 44 " years old. More than half of the risk managers hold a master's degree while only $6 \%$ of them are $\mathrm{PhD}$ graduates. $40 \%$ of the respondents are graduates of 4 -year university programs. Almost half of the risk managers (47\%) have a monthly income of TRY "10.001 to TRY 15.000 ", and only $6 \%$ of below TRY 5.000 .

Nearly two-thirds of the respondents (62\%) are managers of Internal Control/Risk Management departments. $18 \%$ of the respondents serve as manager of Audit/Internal Audit department, and 12\% as manager of Risk Management, $4 \%$ as manager of Compliance, and $2 \%$ as CFO, and $2 \%$ as CEO.

As for the total year of experience that respondents have in risk management; more than one-third of them (38\%) have a background of " 5 to 10 years", and $32 \%$ of them " 10 to 15 years" in risk management area.

As for roles that risk managers in the survey took before taking over their current role; most of them (61\%) worked for the departments of audit, internal audit, internal control and risk management while almost one-fourth of them (24\%) worked for the department of finance.

Only half of the respondents have a training course and held a certificate about risk management.

Most (82\%) of the risk managers or insurance companies that they work for are not a member of any risk management association.

\subsection{Analysis of Survey Data}

\subsubsection{General Information about Insurance Companies that Respondents Work For}

Two-thirds $(66 \%)$ of the insurance companies that respondents work for operate in non-life insurance companies while $34 \%$ of them operate in life and pension insurance companies. $71 \%$ of life and pension insurance companies have a foreign capital while $64 \%$ of non-life insurance companies have a foreign capital.

Nearly one-third $(36 \%)$ of the insurance companies that respondents work for employ more than 301 staff members, and $16 \%$ of them " 1 to 50 ".

Nearly one-third of the insurance companies that respondents work for have had a negative EBITDA ratio for the past 5 years. $19 \%$ of them have had a ratio over $20 \%$, and most of them operate in life and pension insurance. 
Half (50\%) of the insurance companies that respondents work for are companies of a main European shareholder while nearly one-third of them are companies of Turkish capital. $8 \%$ of them have main shareholders based in the Middle East, $6 \%$ in America and 2\% in Asia-Pacific countries.

Only $12 \%$ of the insurance companies that respondents work for are publicly traded.

\subsubsection{General Information about the Structure of Risk Management Departments of Insurance Companies}

Most (86\%) of the insurance companies have a dedicated risk management department and only $14 \%$ of them do not have a dedicated risk management department as it is affiliated to other departments. Even though there is no obligation set out in the local legislation to have a dedicated risk management department, $86 \%$ of insurance companies have a dedicated department and this is a testament to the importance attached by insurance companies to risk management. $67 \%$ of the companies with a dedicated risk management department are foreign-capital companies. $60 \%$ of the companies with a dedicated risk management department operate in non-life insurance. All the publicly traded companies have a dedicated risk management department. All the companies with a dedicated risk management department have set clear and specific roles for the risk management department. $76 \%$ of them employ " 1 to 3 " staff members for the risk management department. The employees of $65 \%$ of them hold a master's degree or $\mathrm{PhD} .91 \%$ the insurance companies with a dedicated risk management department officially report to the top management for more than once a year.

Most (94\%) of the insurance companies that respondents work for have clear and specific roles for the risk management department.

At $40 \%$ of the insurance companies, the risk management department has been operating for " 1 to 5 " years, and $42 \%$ of them for " 6 to 10 " years, $16 \%$ of them for " 11 to 15 " years and only $2 \%$ of them for over 16 years. $67 \%$ of the companies with a dedicated separate risk management department operating for over 10 years are European-capital companies, and all of them have a clear and specific role.

Nearly two-thirds (66\%) of the insurance companies that respondents work for have a separate risk committee within their body. $79 \%$ of the companies with a risk committee are foreign-capital companies while $67 \%$ of them operate as a non-life insurance company.

As a part of the survey, the risk managers were asked about reporting to the top management and provided with multiple options to choose from. Most $(65,3 \%)$ of the managers from the risk management department at insurance companies report to a CEO and $38,8 \%$ of them report to board members and then to a risk committee, chairman of the board, CFO and CRO respectively (Figure 1).

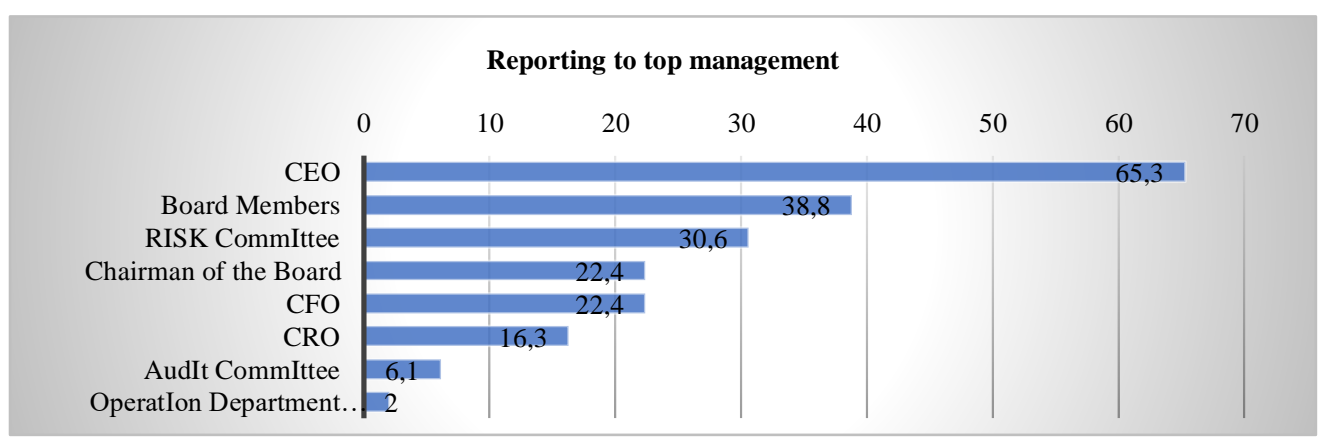

Figure 1. Reporting to top management

The vast majority $(90 \%)$ of the managers of risk management departments at insurance companies that respondents work for officially report for more than once, usually 4 times a year to the top management. Very few of the insurance companies do not have any formal procedures or report once a year.

As a part of the survey, the risk managers were asked about cooperation with other departments and provided with multiple options to choose from. The departments of risk management at insurance companies that respondents work for are in cooperation the most with the department of internal audit $(87,8 \%)$ and finance $(85,7 \%)$. It is followed by the departments of law department, compliance, actuary, and then by technical service $\&$ operations and information technologies. The department of human resources is the department that other departments cooperate with the least (Figure 2). 


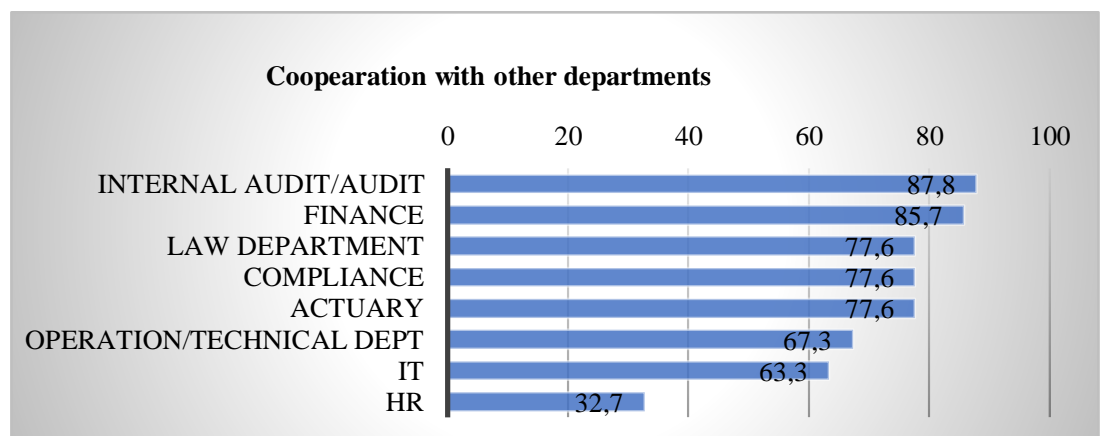

Figure 2. Cooperation of the risk management department with other departments

Most of the companies (84\%) have a regular procedure for other departments in the company to submit, report and send related documents to the risk management department.

In general, resolutions taken by the departments of risk management of nearly half (47\%) of the insurance companies are highly influential on corporate business process while it is moderately influential for nearly one-third of them (35\%) (Figure 3).

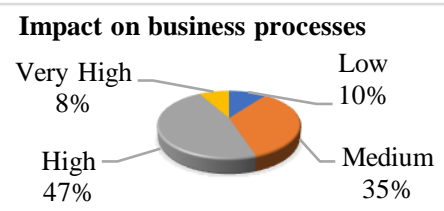

Figure 3. Impact of resolutions of the risk management department on corporate business process

Nearly one-third (31\%) of the employees of other departments at insurance companies are in cooperation with the risk management department at the "very high" level, with nearly one-third of them (35\%) at a "high" level, and $28 \%$ of them at a "medium" level (Figure 4 ).

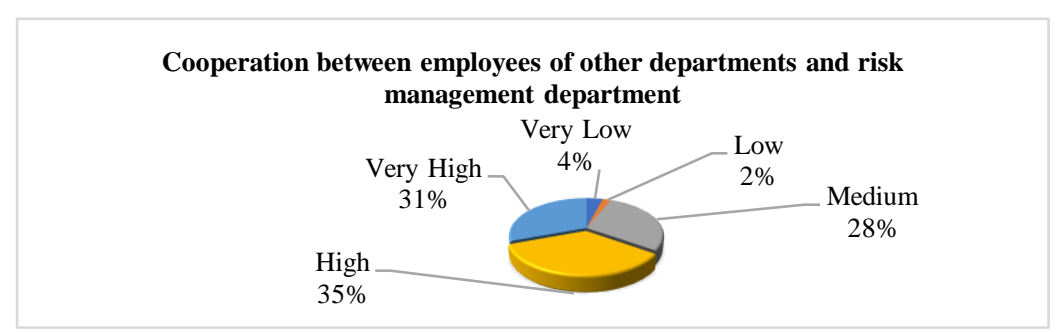

Figure 4. Cooperation of employees from other departments with the risk management department

The recommendations of the employees from other departments about risk management are taken into account at the "very high" level by $31 \%$ of the companies, and at a "high" level by $41 \%$ of them (Figure 5 ).

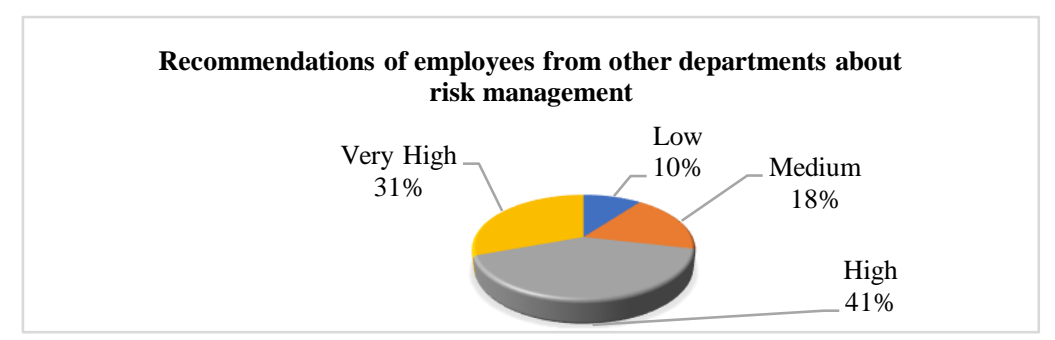

Figure 5. Recommendations of employees from other departments about risk management

\subsubsection{General Information on Risks of Insurance Companies and Their Strategies to Deal with Them}

Most of the insurance companies (84\%) have set a risk appetite and risk capacity. $66 \%$ of the companies that set a risk appetite and capacity operate in non-life insurance while $65 \%$ of them are foreign-capital companies and $73 \%$ of them employ a total of over 100 staff members. $56 \%$ of them produce over TRY 500 million in premium 
per year. $98 \%$ of the companies that set risk appetite and capacity have clear and specific roles for the risk management department, and $90 \%$ of them have a dedicated risk management department while $60 \%$ of them have a risk committee within their body (Figure 6).

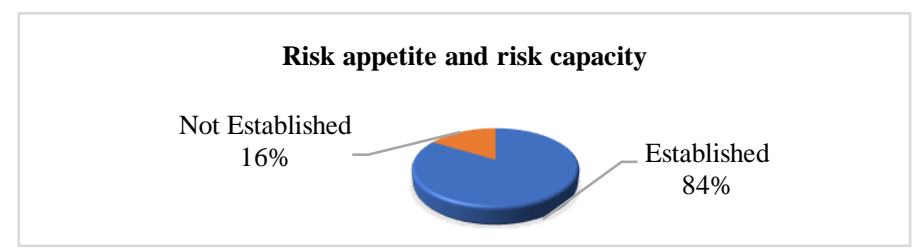

Figure 6. Risk appetite and risk capacity

Most of the insurance companies (90\%) have established a risk management culture. $66 \%$ of the companies that establish a risk management culture operate as a non-life insurance company while $73 \%$ of them are foreign-capital companies and $73 \%$ of them employ a total of over 100 staff members. $59 \%$ of them produce over TRY 500 million in premium per year. $98 \%$ of the companies that establish a risk management culture have clear and specific roles for the risk management department and $91 \%$ of them have a dedicated risk management department while $75 \%$ of them have a risk committee within their body (Figure 7).

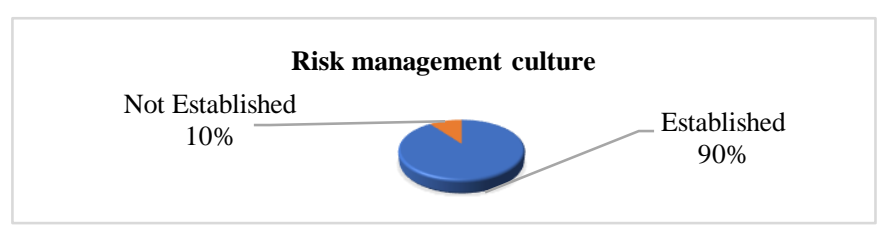

Figure 7. Risk management culture

$96 \%$ of the insurance companies have risk strategies (risk identification and risk management strategies). $64 \%$ of the companies that set risk strategies operate in non-life insurance while $68 \%$ of them are foreign-capital companies and $72 \%$ of them employ a total of over 100 staff members. $55 \%$ of them produce over TRY 500 million in premium per year. $98 \%$ of the companies that set risk strategies have clear and specific roles for the risk management department and $92 \%$ of them have a dedicated risk management department while $70 \%$ of them have a risk committee within their body (Figure 8).

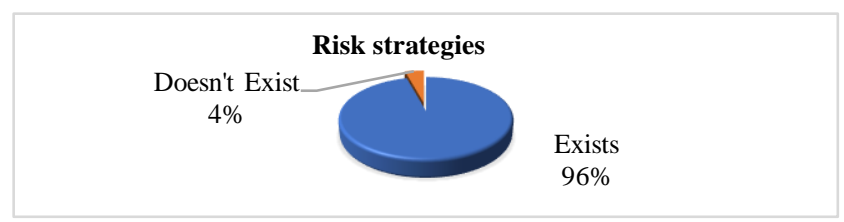

Figure 8. Risk strategies

Based on the responses to the survey, insurance companies, while adopting any risk strategies in order to identify and manage risks, rely on root cause analyses, scenario analyses, risk maps, software-based simulations, international risk assessment methodologies, international standards and frameworks, legislative instruments, risk control self-assessment management, analyses of assets and obligations, credit risk modeling, V@R analyses, brainstorming, risk identification meetings, observations, surveys, interviews, analyses of emerging risk trends, probability-impact matrix, methods of risk analysis, ORSA, MRSA, risk catalogue, risk assessment matrix that embodies COSO cube, risk profiles, key indicators, check lists, SWOT analyses, web-based operational risk measurement software programs, simple scenario analyses on excel for financial risks, Solvency II criteria and risk appetite documents.

$68 \%$ of the insurance companies (nearly two-thirds) revise risks once a year while $30 \%$ of them revise them more than once a year. Very few of them (2\%) revise them once every 3 years. The majority of the companies that revise risks for multiple times a year have set their risk appetite and risk capacity, and all of them have adopted risk strategies and established a risk management culture while $87 \%$ of them have a risk committee within their body, along with clear and specific roles of reference for the risk management department, and also have a dedicated risk management department, and $87 \%$ of them are foreign-capital companies while most of them have a positive EBITDA ratio (Figure 9). 


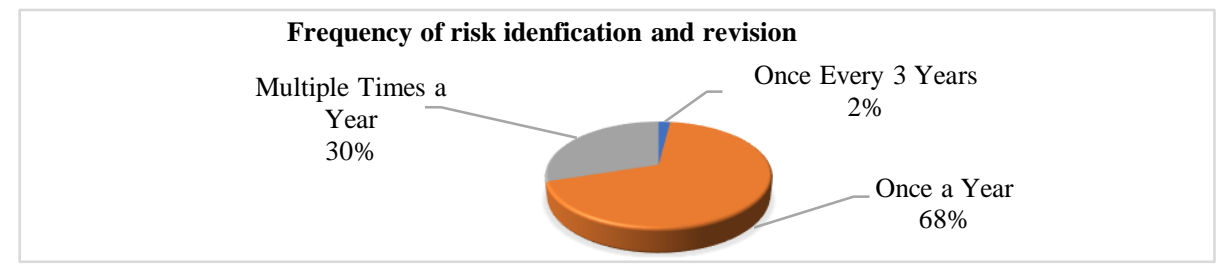

Figure 9. Frequency of risk identification and revision

Main functions of risk management departments at most of the insurance companies are: "development of risk maps, risk identification, analysis and assessment, design and practice of risk checks, development of a corporate-wide risk culture, development of a strategy to set risk appetite, making risk management a part of any business strategy, development of a strategy to measure risk capacity, and business continuity management". Over $95 \%$ of the insurance companies have the functions to develop risk maps and design and implement risk checks. As for insurance companies where functions to both develop risk maps and design and implement risk checks are fulfilled by the risk management department, the majority of them have set their risk appetite and risk capacity, established their risk management culture, adopted risk strategies, provided the risk management department with cooperation with other departments, made sure resolutions taken by the risk management department have an impact on corporate business process, have other departments report to the risk management department and take recommendations of employees from other departments about risk management into consideration.

As for whether or not functions that a risk management department is supposed to fulfill, over $93 \%$ of the insurance companies manage to fulfill functions of "compliance and legislative policies, corporate insurance management and loss prevention, design of risk checks, design of internal auditing procedures and business continuity". Risk financing strategies and integration of risk management as a part of any business strategy are major functions to be rolled out within the next 3 years by more than $20 \%$ of the insurance companies. Reputation, social responsibility, projects of information technologies and risk financing strategies are some of the functions that have yet to be planned by more than $20 \%$ of the insurance companies (Figure 10).

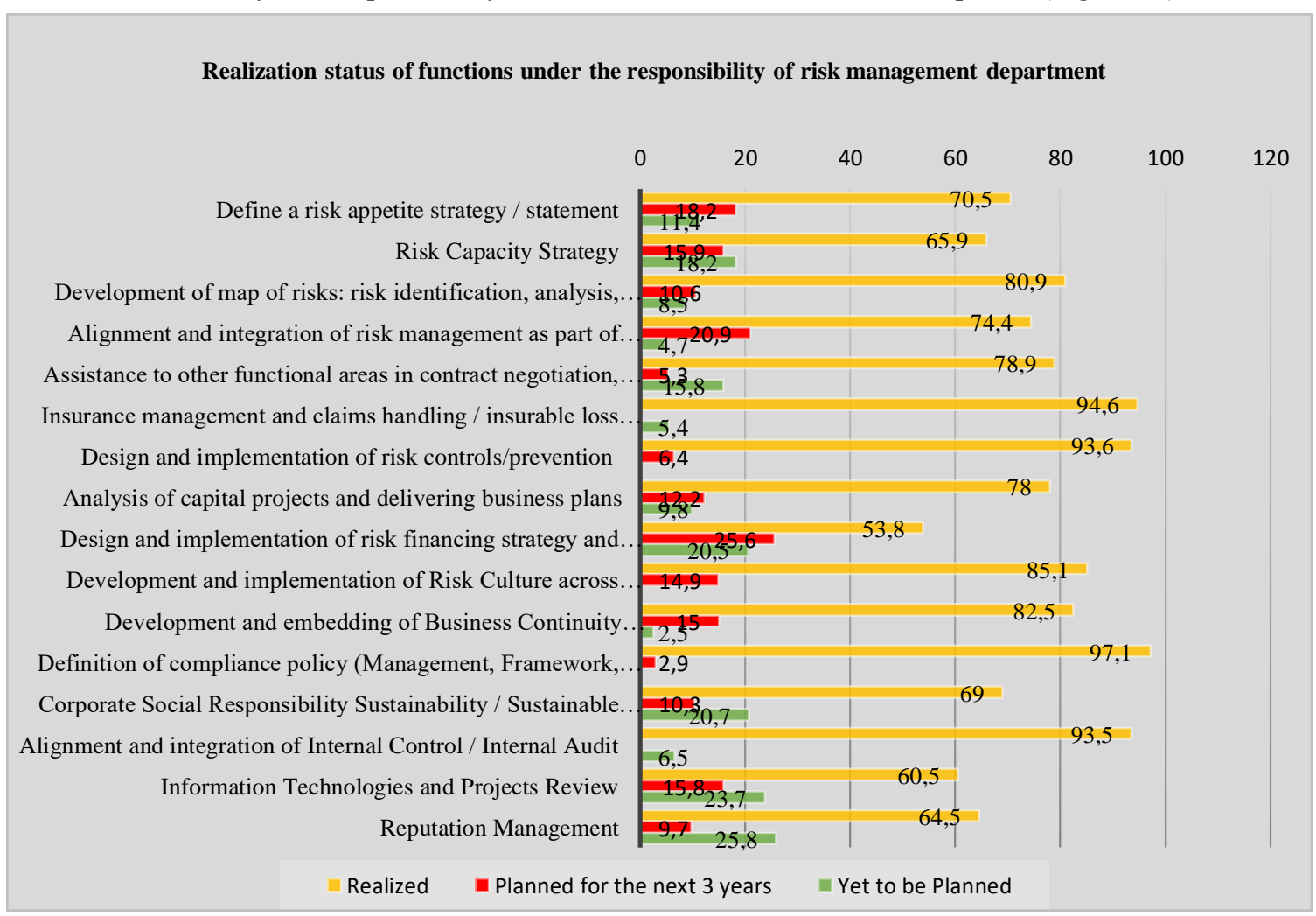

Figure 10. Realization status of the functions that are under the responsibility of the risk management dept. 
Regarding risk management, "Risk Awareness/Identification/Risk Prevention" trainings are offered in most of $(58, \%)$ insurance companies. Trainings for the "Assessment and Benchmarking of Existing Risks" are offered in $39,6 \%$ of companies (Figure 11).

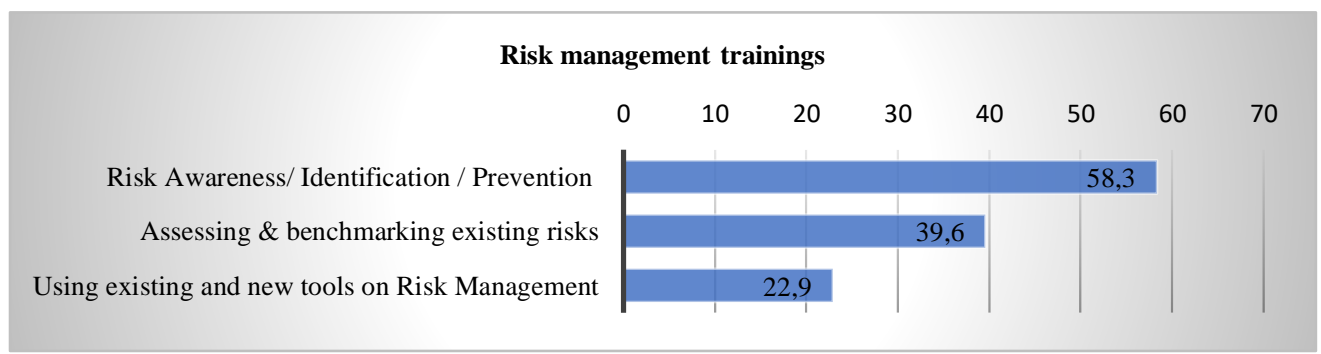

Figure 11. Risk management trainings

Insurance companies use information technologies and tools particularly for "Tracing risk mitigation activities, Risk recording and Risk mapping". More than $62 \%$ of companies use these three functions heavily. Following that, Risk appetite, Scenario analyses and Identification of risk capacity are used in more than $50 \%$ of companies. Representing the lowest ratio, only $25 \%$ of insurance companies use insurance policies they have bought for themselves in claim analysis (Figure 12).

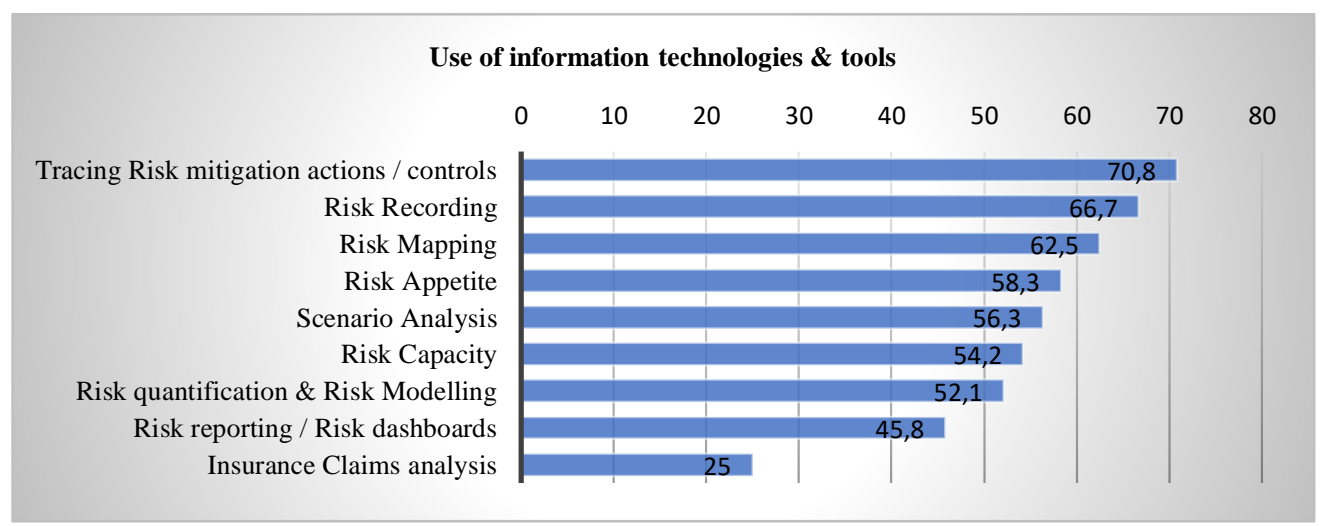

Figure 12. Use of information tools and technologies

Risk managers were asked a question about "their highest risks" and were given the right for multiple choices. The highest risks that would pose a threat to attaining strategic achievement were reported as "Interest rate and exchange rate fluctuation, political risks, economic slowdown, economic crisis, regulatory changes, cyber-attacks, non-compliance with the legislations, increasing competition, digitalization/insurtech and business continuity interruption risks", respectively. "Contract management, fraud, bribery, demographic risks, environment and sustainability and penalties for company managers" were considered as the lowest risks. Looking at the insurance companies that reported all the following as the high risks to pose a threat, one sees that: $60 \%$ of them are non-life insurance companies, $60 \%$ of them are foreign-capitalized, $80 \%$ of them have risk strategies, $70 \%$ of them have a risk culture and $70 \%$ of them have identified risk appetite and capacity (Table 2 , Column 3).

When the risks that would pose a threat for insurance companies to attaining strategic achievement were subjected to "Impact x Likelihood (5x5 Matrix) Risk Scoring", the ratio of risk scores within the whole were reported as "Economic crisis, political risks, interest rate and exchange rate fluctuation, economic slowdown, regulatory changes, cyber-attacks, increasing competition, digitalization, non-compliance with the legislations and information technologies", respectively. "Contract management, environment and sustainability, penalties for company managers, new ways of communication and social media, fraud, bribery and demographic risks" were considered as the lowest risks in risk scoring (Table 2, Column 2).

While interest rate and exchange rate fluctuation risks are in the top in the list for highest risks considered as a threat by companies; since economic crisis is listed in the top in risk scoring, one sees that economic crisis will have greater impacts on insurance companies. The remaining political risks and instability, economic slowdown, 
regulatory changes and cyber risks were in parallel for both categories; while information technologies and data center risks had higher degrees in risk scoring compared to the business continuity interruption risk.

The highest risks foreseen by insurance companies to be influential in the next 5 years are as follows: "Political risks, economic crisis, regulatory changes, economic slowdown and interest rates/exchange rate fluctuation, information technologies and digitalization/insurtech, environmental risks, cyber risks and increasing competition". "Innovation and change method, terrorism, brand image and reputation, debt/cash flow and human resources" were considered as the lowest risks that might have effects on insurance companies in the next 5 years (Table 2, Column 1).

Table 2. Risks foreseen by insurance companies in Turkey

\begin{tabular}{ccc}
\hline $\begin{array}{c}\text { The Highest Risks to be Faced by Insurance } \\
\text { Companies in the Next } 5 \text { Years }\end{array}$ & $\begin{array}{c}\text { Risk Scoring Ranking of the } \\
\text { Highest Risks }\end{array}$ & $\begin{array}{c}\text { Ranking of the Highest Risks to Pose a } \\
\text { Threat for Insurance Companies }\end{array}$ \\
\hline Political Risks & Economic Crisis & Interest Rate/Exch. Rate Fluctuation \\
Economic Crisis & Political Risks & Political Risks \\
Regulatory Changes & Interest Rate/Exch. Rate Fluctuation & Economic Slowdown \\
Economic Slowdown & Economic Slowdown & Economic Crisis \\
Interest Rate/Exch. Rate Fluctuation & Regulatory Changes & Regulatory Changes \\
Information Technologies & Cyber Risks & Cyber Risks \\
Digitalization/InsurTech & Increasing Competition & Non-Compliance with Legislation \\
Environmental Risks & Digitalization/InsurTech & Increasing Competition \\
Cyber Risks & Non-Compliance with Legislation & Digitalization/InsurTech \\
Increasing Competition & Information Technologies & Business Continuity Interruption \\
\hline
\end{tabular}

The highest risks that would pose a threat for insurance companies to attaining strategic achievement are "Political risks, economic slowdown, economic crisis, environmental risks, interest rate change/and exchange rate fluctuation in terms of Risk Undertaking/Accepting Strategies. Most insurance companies are observed to have undertaken these risks. On the other hand, they are observed to have preferred risk improvement or risk transfer over risk undertaking for the risks of "brand image/reputation, digitalization/insurtech, Market strategies, Non-compliance with the legislation, Human resources, Service quality, Information technologies, Business continuity interruption and cyber-attacks" (Figure 13).

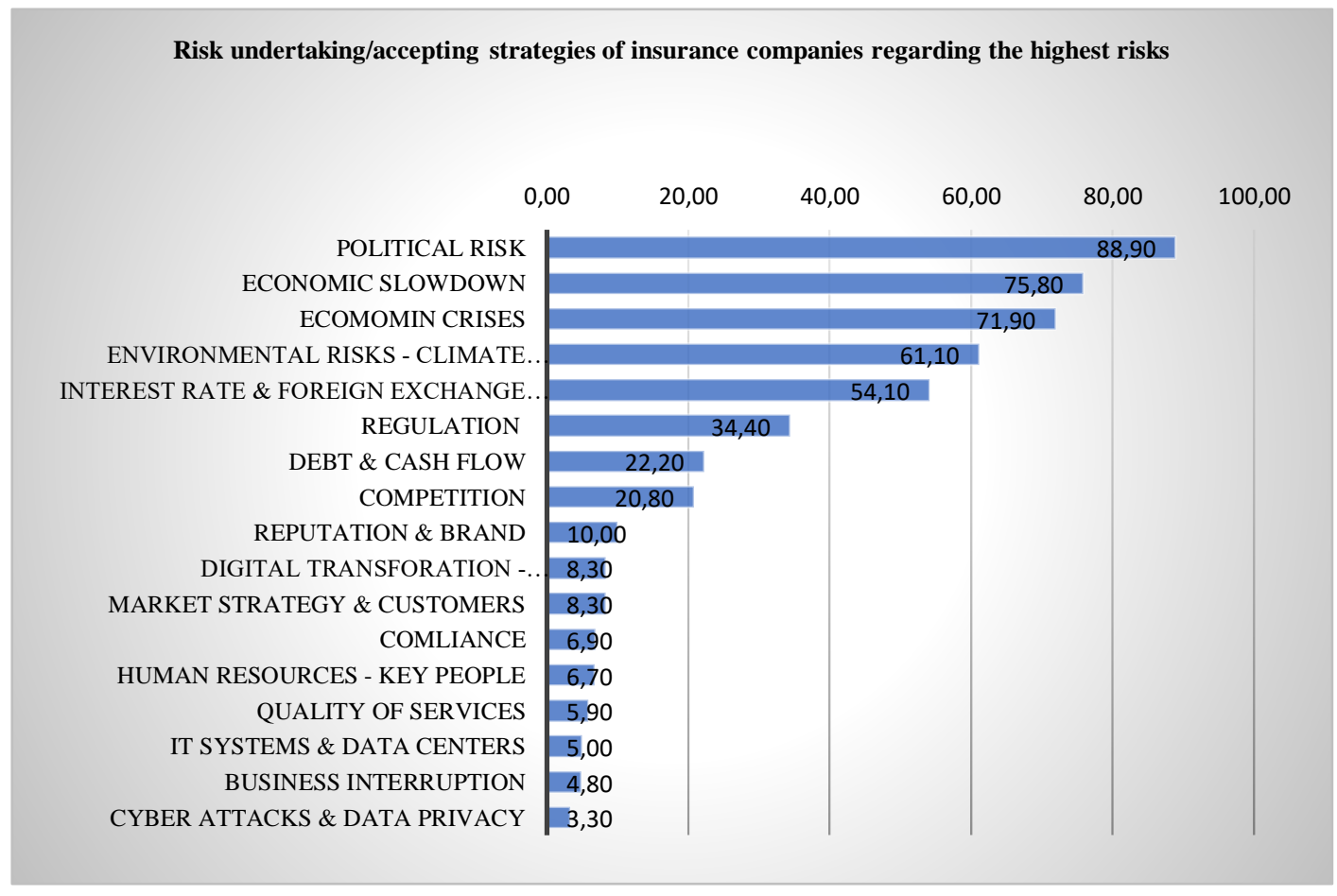

Figure 13. Risk undertaking/accepting strategies of insurance companies regarding the highest risks 
4.2.4 General Information about the Insurance Policies that Insurance Companies Have Bought for Their Risk Management

More than half (58\%) of the insurance companies buy an insurance policy for themselves through an insurance intermediary company. When buying an insurance policy for themselves, insurance companies particularly use "previous insurance claim experiences and possible maximum loss/PML" criteria to designate their policy limits. Assessment made within the framework of Corporate Risk Management Strategies and Budget Limits criteria remain at a low level. Looking at the insurance companies using previous insurance claim experiences and possible maximum loss/PML criteria together one sees that; $87 \%$ of them are non-life insurance companies, $56 \%$ of them are foreign-capitalized, $83 \%$ of them have a separate risk management department, $74 \%$ of them have a risk committee, $91 \%$ of them have an established risk culture, $83 \%$ of them have identified risk appetite and capacity and $91 \%$ of them have risk strategies (Figure 14).

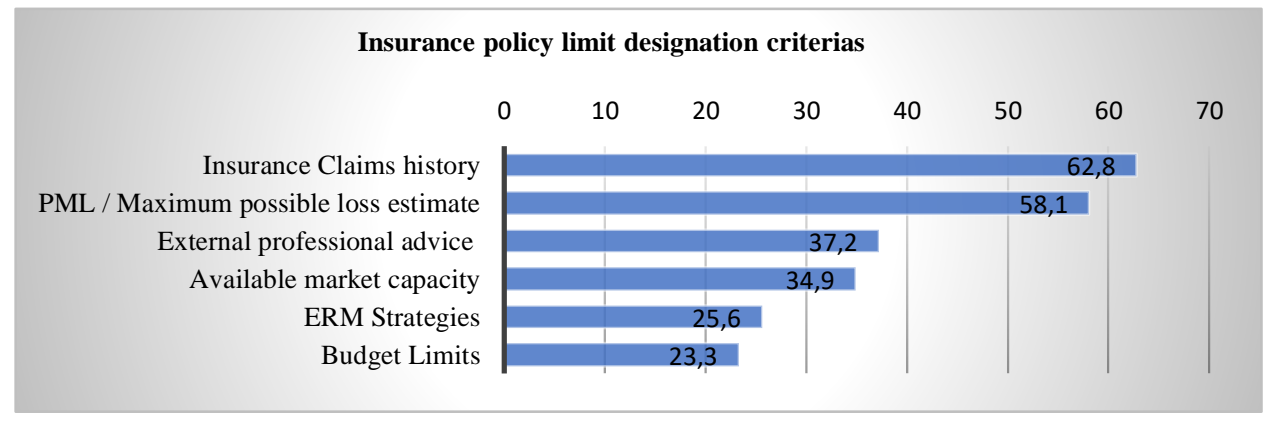

Figure 14. Criteria for designating policy limits for insurance companies

"Claim management procedures, policy wording and claim reporting" are among the items insurance companies have developed/improved in the last 3 years in the "Loss Control and Loss Mitigation Management Processes" available in the insurance policies they have bought for all their risks including their own assets and liabilities. Main items with the lowest development/improvement rate are: "crisis management simulations, selection of insurance loss adjuster expert prior to the execution of policy and receiving a loss advance payment within 30 days from insurers" (Figure 15).

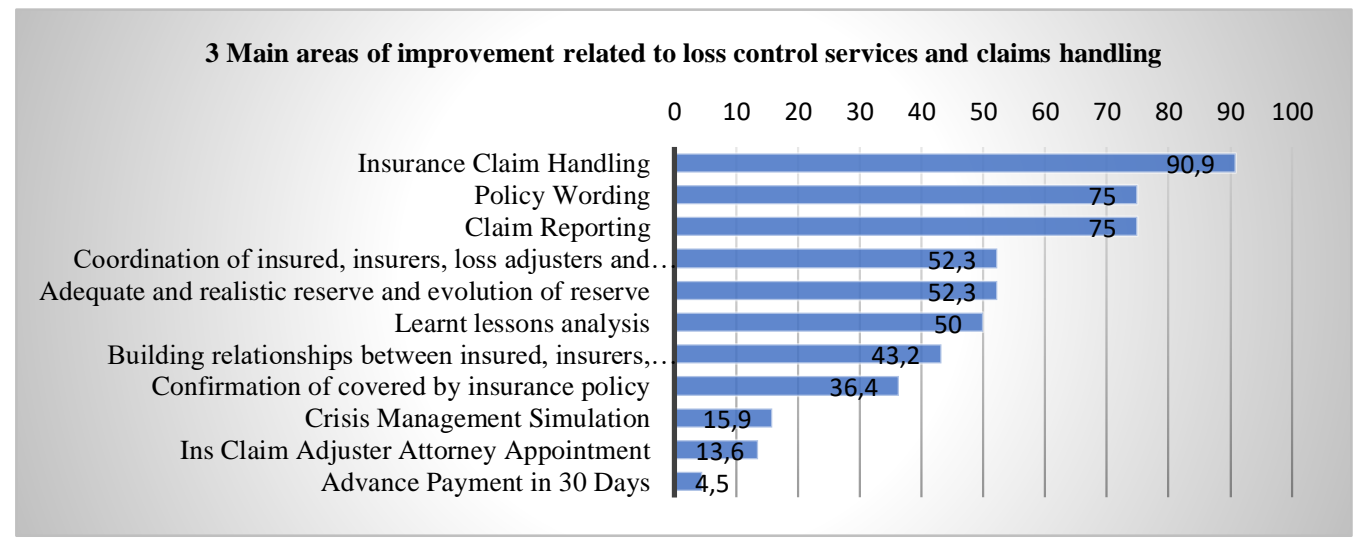

Figure 15. The main items insurance companies have developed/improved in the last 3 years

Looking at the subjects/fields the insurance companies have developed/improved in terms of Loss Control and Claim Management Services in the last 3 years independent from the insurance policies that they have bought for all their risks including their own assets and liabilities, particularly "the property damage $\&$ business interruption and cyber risks" of insurance companies come to the forefront. $3^{\text {rd }}$ party liability risks of insurance companies are the subject presenting the lowest development/improvement rate.

Insurance companies analyze the claims on the insurance policies they have bought for all their risks including their own assets and liabilities and use the data of such loss/claim particularly in the "optimization of the policy limits and the level of retention in these policies". There are only few companies that analyze insurance loss/claim data and assume no connection with insurance and risk, suggesting that most insurance companies prognosticate the need to analyze loss data and to identify the limits\&retention of insurance policies (Figure 16). 


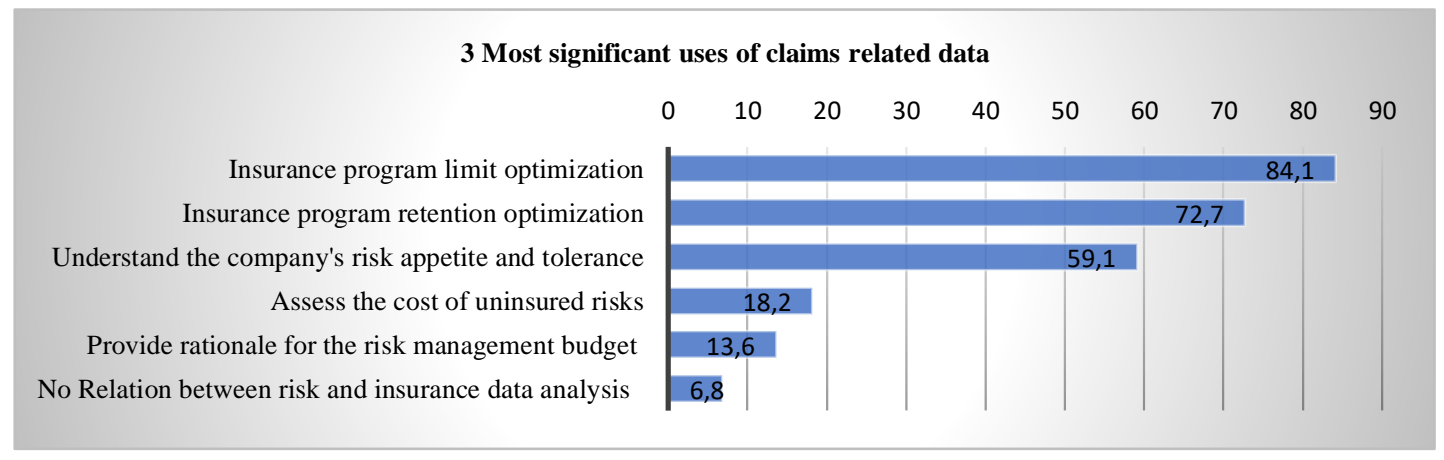

Figure 16. Uses of claim data

\subsubsection{Analysis of Survey Data by Non-Parametric/Chi-Square Tests}

Survey data was assessed by SPSS 22 Statistics Software and the data obtained was subjected to non-parametric chi-square tests. Hypotheses $\left(\mathrm{H}_{0}\right)$ and $\left(\mathrm{H}_{1}\right)$ in these tests are as follows:

Hypothesis $\mathrm{H}_{0}$ : There is no relation/difference between these two groups.

Hypothesis $\mathrm{H}_{1}$ : There is relation/difference between these two groups.

In Chi-Square test, $\left(\mathrm{H}_{0}\right)$ is rejected for results with an Asymptotic Sigma value less than 0,05 so, $\left(\mathrm{H}_{1}\right)$ is accepted. $\left(\mathrm{H}_{1}\right)$ shows that the mean values of these two variables are not equal, indicating a relation between them. Also, Fisher's Exact Test was applied for cases where the frequency of data was less than " 5 " in the tests. $\left(\mathrm{H}_{1}\right)$ is accepted with Sigma values less than 0,05. Additionally, Yates Correction (Continuity Correction) and Likelihood Ratio tests were examined (Table 4).

Chi-Square Test: Is there a relation between the "principal main shareholder's being Turkish or foreign capitalized" and the "establishment of a risk management culture in the company"? (Table 3).

$\mathrm{H}_{0}$ : There is no relation between the "principal main shareholder's being Turkish or foreign capitalized" and the "establishment of a risk management culture in the company"

$\mathrm{H}_{1}$ : There is relation between the "principal main shareholder's being Turkish or foreign capitalized" and the "establishment of a risk management culture in the company"

Table 3. Non-Parametric Chi-Square test / data set

\begin{tabular}{lrccc}
\hline & & \multicolumn{2}{c}{$\begin{array}{c}\text { Has the Company Established } \\
\text { Risk Management Culture? }\end{array}$} & \multirow{2}{*}{ Total } \\
\cline { 3 - 4 } & & Yes & No & \\
What is the Origin of the & Turkey & 12 & 5 & 17 \\
Company's Main Shareholders? & Other Countries/Foreign Capital & 32 & 0 & 32 \\
& Total & 44 & 5 & 49 \\
\hline
\end{tabular}

Table 4. Non-Parametric Chi-Square test / results

\begin{tabular}{|c|c|c|c|c|c|}
\hline & Value & df & $\begin{array}{c}\text { Asymp. Sig. } \\
\text { (2-sided) }\end{array}$ & $\begin{array}{c}\text { Exact Sig. } \\
\text { (2-sided) }\end{array}$ & $\begin{array}{l}\text { Exact Sig. } \\
\text { (1-sided) }\end{array}$ \\
\hline Pearson Chi-Square & $10.481^{\mathrm{a}}$ & 1 & 0.001 & & \\
\hline Continuity Correction ${ }^{\mathrm{b}}$ & 7.517 & 1 & 0.006 & & \\
\hline Likelihood Ratio & 11.698 & 1 & 0.001 & & \\
\hline Fisher's Exact Test & & & & 0.003 & 0.003 \\
\hline Linear-by-Linear Association & 10.267 & 1 & 0.001 & & \\
\hline $\mathrm{N}$ of Valid Cases & 49 & & & & \\
\hline
\end{tabular}

a. 2 cells $(50.0 \%)$ have expected count less than 5 . The minimum expected count is 1.73 .

b. Computed only for a $2 \times 2$ table. 
Findings: $\left(\mathrm{H}_{0}\right)$ is rejected as sigma values are less than 0,05 and $\left(\mathrm{H}_{1}\right)$ is accepted. $\left(\mathrm{H}_{1}\right)$ shows that the mean values of these two variables are not equal, indicating a relation between them. Whether the "principal main shareholder's being Turkish or foreign-capitalized" changes depending on the "company has established a risk management culture", suggesting a relation between them.

The results of other Chi-Square tests are presented below along with the other similar assessments (Table 5).

Table 5. Chi-Square test results \& findings

\begin{tabular}{|c|c|c|c|}
\hline & Hypothesis & Sigma Values & Findings \\
\hline 1 & $\begin{array}{l}\text { Is there a relation between the "principal main shareholder's being Turkish or foreign } \\
\text { capitalized" and the "establishment of a risk management culture in the company"? }\end{array}$ & 0,001 & $\begin{array}{l}\text { There is } \\
\text { relation }\end{array}$ \\
\hline 2 & $\begin{array}{l}\text { Is there a relation between the "presence of a separate risk management department in the } \\
\text { company" and the "company's having established risk strategies"? }\end{array}$ & 0,000 & $\begin{array}{l}\text { There is } \\
\text { relation }\end{array}$ \\
\hline 3 & $\begin{array}{l}\text { Is there a relation between the "principal main shareholder's being Turkish or foreign } \\
\text { capitalized" and "other departments" reporting to risk management department regularly"? }\end{array}$ & 0,009 & $\begin{array}{l}\text { There is } \\
\text { relation }\end{array}$ \\
\hline 4 & $\begin{array}{l}\text { Is there a relation between the "principal main shareholder's being Turkish or foreign } \\
\text { capitalized" and the "presence of separate risk committee in the company"? }\end{array}$ & 0,008 & $\begin{array}{l}\text { There is } \\
\text { relation }\end{array}$ \\
\hline 5 & $\begin{array}{l}\text { Is there a relation between the "company's being a life/non-life insurance company" and the } \\
\text { "company's having used the PML criteria when defining its own insurance policy limits"? }\end{array}$ & 0,017 & $\begin{array}{l}\text { There is } \\
\text { relation }\end{array}$ \\
\hline 6 & $\begin{array}{l}\text { Is there a relation between the "presence of separate risk committee in the company" and the } \\
\text { "establishment of a risk management culture in the company"? }\end{array}$ & 0,001 & $\begin{array}{l}\text { There is } \\
\text { relation }\end{array}$ \\
\hline 7 & $\begin{array}{l}\text { Is there a relation between the "establishment of a risk management culture in the company" } \\
\text { and "realization of design, application of risk controls or prevention of risks in the company"? }\end{array}$ & 0,001 & $\begin{array}{l}\text { There is } \\
\text { relation }\end{array}$ \\
\hline 8 & $\begin{array}{l}\text { Is there a relation between the "establishment of a risk management culture in the company" } \\
\text { and "offering risk awareness/identification/prevention trainings to company personnel"? }\end{array}$ & 0,006 & $\begin{array}{l}\text { There is } \\
\text { relation }\end{array}$ \\
\hline 9 & $\begin{array}{l}\text { Is there a relation between the "company's having established risk strategies" and "realization } \\
\text { of design, application of risk controls or prevention of risks in the company"? }\end{array}$ & 0,000 & $\begin{array}{l}\text { There is } \\
\text { relation }\end{array}$ \\
\hline 10 & $\begin{array}{l}\text { Is there a relation between the "company's having established risk strategies" and "other } \\
\text { departments' reporting to risk management department regularly"? }\end{array}$ & 0,001 & $\begin{array}{l}\text { There is } \\
\text { relation }\end{array}$ \\
\hline
\end{tabular}

\section{Conclusion}

According to the non-parametric Chi-Square test findings of the survey data, it is seen that there are relations between groups given below.

There is relation between "principal main shareholder's being Turkish or foreign capitalized" and "establishment of a risk management culture in the company".

There is relation between "presence of a separate risk management department in the company" and "company's having established risk strategies".

There is relation between "presence of separate risk committee in the company" and "establishment of a risk management culture in the company".

There is relation between "establishment of a risk management culture in the company" and "realization of design, application of risk controls or prevention of risks in the company".

There is relation between "company's having established risk strategies" and "realization of design, application of risk controls or prevention of risks in the company".

There is relation between "company's having established risk strategies" and "other departments" reporting to risk management department regularly".

According to global and Turkish insurance market 2018 data, Turkish Insurance sector has an extraordinarily little share in the world insurance sector premium yield, with a share of $0,22 \%$. While the ratio of premium to GDP is $6,09 \%$ in the world, the ratio in Turkey is $1,33 \%$, which is just one fourth of this. While the per capita premium yield is around USD 682 in the world, this is just USD 127 in Turkey, representing around one fifth of this ratio, indeed. While the world insurance sector has grown 1,5\%, the Turkish insurance sector has decreased $1,46 \%$ in real terms. The Turkish insurance market is rather small in the global arena and the Turkish insurance sector has only share of $4,17 \%$ in the total assets of the whole Turkish financial sector. 
Despite the small size of the Turkish insurance market, the insurance sector has great tasks due to the fragile national state and the major risks it faces. The insurance sector needs a strong risk management system in order to fulfil its function. The following are among the most important findings of a relevant survey study. Although there is no obligation in local legislation, most insurance companies have a separate risk management department with clearly defined tasks, more than half of the companies have a risk committee and risk management reports are quarterly submitted to the top management in general. Risk managers particularly act in close cooperation with the internal audit, finance and law departments, i.e., with other key decision-makers and risk management department regularly receives reports from other departments in most of the companies. The decisions taken by risk management departments are observed to have a great influence on general business processes of the companies. In addition, risk appetite and risk capacity are established in most of the companies and they have a risk management culture. Companies also have identified their risk strategies, which are revised at least once a year. The functions under the responsibility of risk management departments have been defined and most of them have been realized in many insurance companies, and a small part is to be realized in the next 3 years. Trainings such as risk awareness/risk prevention are offered in most of the companies. The use of information tools and technologies for functions such as risk mapping and tracing of risk activities are also among the important findings. In addition to these findings, top 10 risks foreseen by insurance companies are "interest rate and exchange rate fluctuation, political risks, economic slowdown, economic crisis, regulatory changes, cyber risks, non-compliance with the legislation, increasing competition, digitalization/insurtech and business continuity interruption risks".

Although the Turkish insurance sector has a small share both in the global insurance market and in the Turkish financial sector, the findings of the survey suggest that it is strong in terms of the risk management structure.

\section{References}

Acharyya, M., \& Johnson, J. (2006). Investigating the Development of Enterprise Risk Management in The Insurance Industry: An Empirical Study of Four Major European Insurers. Retrieved from https://www.actuaries.org.uk/system/files/documents/pdf/acharyya.pdf

Acharyya, M., \& Mutenga, S. (2013). The Benefits of Implementing Enterprise Risk Management: Evidence from the U.S. Non-Life Insurance Industry. Enterprise Risk Management Symposium - Casualty Actuarial Society, Professional Risk Managers' International Association, Society of Actuaries. Retrieved from https://www.soa.org/globalassets/assets/files/resources/essays-monographs/2013-erm-symposium/mono-20 13-as13-1-acharyya.pdf

Acharyya, M. (2008). An Empirical Study on Enterprise Risk Management in Insurance. New Frontiers in Enterprise Risk Management Book, Springer, Berlin, Heidelberg Chapter 4, 39-55. https://doi.org/10.1007/978-3-540-78642-9_4

Altuntas, M., Berry-Stolzle, T., \& Hoyt, R. E. (2011). Implementation of Enterprise Risk Management: Evidence from the German Property-Liability Insurance Industry. The Geneva Papers on Risk and Insurance - Issues and Practice, 36, 414-439. https://doi.org/10.1057/gpp.2011.11

Cohen, J., Krishnamoorthy, G., \& Wright, A. (2017). Enterprise Risk Management and the Financial Reporting Process. Contemporary Accounting Research, 34(2), 1178-1209. https://doi.org/10.1111/1911-3846.12294

Deighton, S. P., Dix, R. C., Graham, J. R., \& Skinner, J. M. E. (2009). Governance and Risk Management in United Kingdom Insurance Companies. British Actuarial Journal - Cambridge University Press, 15(3), 503-556. https://doi.org/10.1017/S1357321700005729

Federation of European Risk Management Associations. (2018). FERMA European Risk Manager Survey Report 2018. Retrieved from https://www.ferma.eu/publication/2018-european-risk-manager-report/

Gahin, F. S. (1971). Review of the Literature on Risk Management. The Journal of Risk and Insurance, 38(2), 309-313. doi: $10.2307 / 251507$

Gamba, A., \& Triantis, A. J. (2013). Corporate Risk Management: Integrating Liquidity, Hedging, and Operating Policies. Management Science, 60(1), 246-264. https://doi.org/10.1287/mnsc.2013.1752

Gordon, L. A. (2009). Enterprise Risk Management and Firm Performance: A Contingency Perspective. Journal of Accounting and Public Policy, 28(4), 301-327. https://doi.org/10.1016/j.jaccpubpol.2009.06.006

Hitchcox, A. N., Klumpes, P. J. M., McGaughey, K. W., Smith, A. D., \& Taverner, N. H. (2011). ERM for Insurance Companies - adding the investor's point of view. British Actuarial Journal, 16(2), 341-384. https://doi.org/10.1017/S1357321711000122 
Hopkin, P. (2018). Fundamentals of Risk Management (5th ed.). London: Kogan Page.

Hoyt, R. E., \& Liebenberg, A. P. (2011). The Value of Enterprise Risk Management. The Journal of Risk and Insurance, 78(4), 795-822. https://doi.org/10.1111/j.1539-6975.2011.01413.x

Insurance Association of Turkey (TSB). Retrieved from https://www.tsb.org.tr

Jabbour, M. (2011). The Impact of Enterprise Risk Management on Capital Allocation in Insurance Companies. Brunel University London - Brunel Business School. http://dx.doi.org/10.2139/ssrn.1910283

Outreville, J. F. (1998). Risk Management Concepts. In: Theory and Practise of Insurance. Boston: Springer. https://doi.org/10.1007/978-1-4615-6187-3_4

Russel, B. C. (1956). Risk Management: A New Phase of Cost Control. Harvard Business Review, 75-86.

SDK (Turkish Insurance Supervision Board). (2018). Annual Report About Insurance and Private Activities 2018. Retrieved from https://www.hmb.gov.tr/sigortacilik-ve-ozel-emeklilik-raporlari

Skipper, H. D., \& Kwon, W. (2007). Risk Management and Insurance: Perspectives in a Global Economy. Blackwell Publishing.

Sprcic, M. (2013). Corporate Risk Management and Value Creation. Montenegrin Journal of Economics, 9(2), 17-26. Retrieved from http://repec.mnje.com/mje/2013/v09-n02/mje_2013_v09-n02-a12.pdf

SwissRe. (2019). Swiss Sigma No:3/2019 World Insurance: The great pivot east continues. No:3/2019. Zurich: Swiss Re Institute. Retrieved from https://www.swissre.com/institute/research/sigma-research/sigma-2019-03.html

\section{Copyrights}

Copyright for this article is retained by the author(s), with first publication rights granted to the journal.

This is an open-access article distributed under the terms and conditions of the Creative Commons Attribution license (http://creativecommons.org/licenses/by/4.0/). 